\title{
Electroanalytical Investigation on Paracetamol on Boron-Doped Diamond Electrode by Voltammetry
}

\author{
Koffi Konan Martin, Lassine Ouattara* \\ Laboratoire de Chimie Physique, UFR SSMT, Université Félix Houphouët-Boigny de Cocody, Abidjan, \\ Côte d'Ivoire \\ Email: *ouatlassine@yahoo.fr
}

How to cite this paper: Martin, K.K. and Ouattara, L. (2019) Electroanalytical Investigation on Paracetamol on Boron-Doped Diamond Electrode by Voltammetry. American Journal of Analytical Chemistry, 10, 562-578.

https://doi.org/10.4236/ajac.2019.1011039

Received: October 11, 2019

Accepted: November 15, 2019

Published: November 18, 2019

Copyright $\odot 2019$ by author(s) and Scientific Research Publishing Inc. This work is licensed under the Creative Commons Attribution International License (CC BY 4.0).

http://creativecommons.org/licenses/by/4.0/

\begin{abstract}
An electroanalytical method was developed for the direct quantitative determination of paracetamol in tablets based on its oxidation behavior. The electrochemical oxidation and determination of paracetamol were easily carried out on born-doped diamond (BDD) electrode using two voltammetric techniques (CV and DPV). The electrochemical measurements performed by cyclic voltammetric (CV) and differential pulse voltammetry (DPV) techniques were carried out using a cathodically pretreated boron-doped diamond electrode in $\mathrm{HClO}_{4}$ and $\mathrm{KClO}_{4}$ electrolytes. $\mathrm{HClO}_{4}$ was then selected for analytical purposes and scan rate studies were also completed. The oxidation of the paracetamol is found to be irreversible and a diffusion-controlled nature of the paracetamol oxidation peak was established. A linear calibration curve for DPV analysis was constructed in the paracetamol concentration range from 0 $\mu \mathrm{M}$ to $13.87 \mu \mathrm{M}$, with $0.16 \mu \mathrm{M}$ and $0.55 \mu \mathrm{M}$ as the detection and quantification limit respectively.
\end{abstract}

\section{Keywords}

Electroanalytical Method, Boron-Doped Diamond Electrode, Voltammetry, Paracetamol

\section{Introduction}

Paracetamol (N-acetyl-p-aminophenol) is an effective and important analgesic and antipyretic agent used widely to relieve pain related to arthralgia, neuralgia, headache and cancer [1]. In general, paracetamol seems to be safe and appears to have no toxic effects on human's health when taken in normal therapeutic doses 
i.e. less than $1 \mathrm{~g}$ per dose and no more than $4 \mathrm{~g} /$ day [2]. However, large doses, more than $4 \mathrm{~g} /$ day, and chronic use of paracetamol or concomitant use with alcohol or other drugs can cause skin rashes, liver disorders, nephrotoxicity and inflammation of the pancreas. In this case, the precise determination and control of the paracetamol become vital [3]. Moreover, the presence of trace paracetamol in drinking water is of great interest since little is known about potential chronic health effects associated with long term ingestion of these compounds through drinking water [4].

A number of methods are available to determine paracetamol in various types of samples [5]. These methods include capillary electrophoresis (CE) [6], high performance liquid chromatography (HPLC) [7], liquid chromatography-mass spectrometry (LC-MS) [8], UV spectrophotometry [9], HPLC-mass spectrometry and thermogravimetric analysis (TGA) [10]. Unfortunately, these techniques are expensive and need costly maintenance. In recent development, electrochemical sensors have been proven as an inexpensive and simple analytical method with remarkable detection sensitivity, reproducibility and easy to miniaturize rather than other instrumental analysis methods [11]. They have been found to have a wide range of applications in clinical, industrial, environmental and agricultural analysis [12]. In this area, several electrodes, such as gold electrodes [13], platinum electrodes [14], glassy carbon electrodes [15], modified glassy carbon electrodes [16], graphite electrodes [17], carbon paste electrodes [18] and modified carbon paste electrodes [19] [20] have been used for the paracetamol determination. But, some of these electrodes such as platinum, for instance, suffer either from surface poisoning during electrochemical reactions or from lack of stability and reproducibility of electrochemical measurements like graphite materials because of their limited life and their extremely sensitive to temperature fluctuations [21]. For seeking stable electrodes for the determination of paracetamol, our focus was made on boron-doped electrodes. This type of electrode has already shown that it can be used to oxidize paracetamol [20]. The use of boron-doped diamond (BDD) as an electrode substrate is now well established, mainly due to its properties such as a wide potential window in aqueous solutions, low background currents, long term stability, and low sensitivity to dissolved oxygen [20]. Moreover, its metallic character due to the replacement of some carbons by boron atoms has been shown. These properties make BDD particularly suitable for electrochemical studies of analytes with a high oxidation potential [22]. The properties of BDD are commonly affected by morphologic factors and defects in the film, presence of impurities ( $\mathrm{sp}^{2}$ carbon), crystallographic orientation, surface termination (hydrogen or oxygen), and electrochemical pre-treatments of its surface [23]. In the work of Suffredini et al. [24], it has been found a cathodic pre-treatment of the BDD electrode increased dramatically the electroanalytical detection limit of chlorophenols. BDD has also successfully been used for the determination of acetylsalicylic acid (ASA) in its pharmaceutical formulations [25], as well as the determination of aspartame and 
cyclamate in dietary products, individually [26] or simultaneously [27] [28].

In this paper, we describe the use of a cathodically pre-treated BDD electrode for the selective and sensitive determination of paracetamol by differential pulse voltammetry (DPV). The results obtained are compared with other results with different operating conditions and working electrodes.

\section{Experimental}

\subsection{Equipment and Electrodes}

The voltammetric measurements were performed using an AUTOLAB PGSTAT 20 (Ecochemie) connected to a potentiostat equipped with USB electrochemical interface. This system is connected to a three-electrode single compartment glass cell and a computer for data storage and processing. A GPES 4 software was employed to get the voltammograms. The glass electrochemical cell consisted of saturated calomel electrode (SCE) and platinum wire as reference and counter electrode respectively. BDD electrode was used as a working electrode. The surface of the BDD in contact with the electrolyte is $1 \mathrm{~cm}^{2}$. All the $\mathrm{pH}$ values were measured with $\mathrm{pH}$ meter. All the potentials reported in this paper were given against (SCE) electrode at an ambient temperature of $25^{\circ} \mathrm{C}$.

\subsection{Reagents and Materials}

Paracetamol was supplied by laboratoire BAILY-CREAT (France). A stock solution of $1.32^{\star} 10^{-2} \mathrm{~mol} / \mathrm{L}(2 \mathrm{~g} / \mathrm{L})$ of paracetamol was prepared by dissolving an accurate mass of the drug in an appropriate volume of $\mathrm{HCLO}_{4}$ and $\mathrm{KCLO}_{4}$. The working solutions for the voltammetric investigations were prepared by dilution of the stock solution. All solutions were protected from light and used within 24 $\mathrm{h}$ to avoid decomposition. $0.1 \mathrm{M}$ of $\mathrm{HClO}_{4}$ and $0.1 \mathrm{M}$ of $\mathrm{KClO}_{4}$ were used for the supporting electrolyte solutions. Distilled water was used to prepare supporting electrolytes.

\subsection{Calibration Graph for Quantitative Determination}

The stock solution of paracetamol was diluted in $\mathrm{HClO}_{4} 0.1 \mathrm{M}$ to obtain different paracetamol concentrations. In the experimental section, a linear calibration curve for DPV analysis was constructed in the paracetamol concentration range from $0 \mu \mathrm{mol} / \mathrm{L}$ to $13.87 \mu \mathrm{mol} / \mathrm{L}$. The repeatability, accuracy and precision were checked.

\subsection{Working Voltammetric Procedure for Tabled Forms}

Two tablets $(500 \mathrm{mg}$ ) of PCM were ground into a fine powder. An adequate amount of this powder, corresponding to the $13.2 \mathrm{mmol} / \mathrm{L}$ stock solution, was weighed and transferred into a $500 \mathrm{~mL}$ calibration flask. The volume was adjusted with $0.1 \mathrm{M} \mathrm{HClO}_{4}$ or $\mathrm{KClO}_{4}$. The contents of the flask were stirred for 30 minutes to ensure complete dissolution and then diluted with the same electrolyte. 
CV and DPV were used to study the electrochemical behavior or quantification of PCM. The analytical curves were obtained by adding small volumes of PCM stock solution to the carrier electrolyte of $\mathrm{HClO}_{4}$ or $\mathrm{KClO}_{4}$. DP voltamograms were obtained after each dosing.

Prior to the experiments, the BDD electrode was electrochemically pretreated in a solution of $0.5 \mathrm{~mol} \cdot \mathrm{L}^{-1} \mathrm{H}_{2} \mathrm{SO}_{4}$. For that pretreatment, an anodic pretreatment $(+2 \mathrm{~V}, 15 \mathrm{~s})$ is followed by a cathodic one $(-2 \mathrm{~V}, 90 \mathrm{~s})$. Doing so, the BDD surface was first cleaned of all impurities and then made primarily hydrogen [24]. The choice of the pretreatment potential and the procedure are discussed in elsewhere [24].

\section{Results and Discussion}

\subsection{Influence of the Supporting Electrolyte}

The voltammetric investigation of the paracetamol containing $\mathrm{HClO}_{4}$ or $\mathrm{KClO}_{4}$ was performed. Figure 1 illustrates the $\mathrm{CV}$ voltammograms in the absence and in the presence of $13.2 \mathrm{mM}$ of paracetamol either in $\mathrm{HClO}_{4}$ or in $\mathrm{KClO}_{4}$ solution.

No peak is observed in the absence of paracetamol in the two electrolytes (curve $\mathrm{a}$ and $\mathrm{b}$ ). However, an anodic peak is observed at the potential of $0.86 \mathrm{~V}$ in the presence of $13.2 \mathrm{mM}$ of paracetamol in each of the electrolytes used (curve $c$ and $d$ ). That anodic peak could be related to the oxidation of the paracetamol [29].

Figure 1 also shows that for the same quantity of PCM in the electrolyte, the current intensity recorded in $\mathrm{HClO}_{4}$ is higher than that recorded in $\mathrm{KClO}_{4}$. Moreover, no current peak was observed in the backwards of the potential scanning indicating that the PCM oxidation process is irreversible on the BDD electrode. PCM has been made more active to be oxidized in its protonated form. From such a finding, $\mathrm{HClO}_{4}$ has been chosen for further investigation in this work.

\subsection{Influence of PCM Concentration}

Figure 2(a) shows the voltammetric curves recorded on the boron-doped diamond electrode in the potential window of 0 to $1.2 \mathrm{~V} / \mathrm{ECS}$ in $0.1 \mathrm{M} \mathrm{HClO}_{4}$ containing different concentrations of PCM. This figure shows that the anodic current peak increases with the concentration of PCM. In addition, the potential of this oxidation peak shifts to positive values (from 0.80 to $0.86 \mathrm{mV} / \mathrm{SCE}$ ) as the concentration of PCM increases. This result indicates that the PCM oxidation process is irreversible on the BDD electrode even for all concentrations investigated. In Figure 2(b), the plot of the PCM oxidation peak current density versus the PCM concentration leads to a straight line with a slope of $0.0005 \mathrm{~A} . \mathrm{L} / \mathrm{g}$ with $\mathrm{R}^{2}=0.9989$. This result shows that the increase of the oxidation peak current density is directly related to the oxidation of the PCM. The PCM oxidation occurs through a direct electron transfer process between BDD and the organics since it happened in the potential window of water stability on the BDD electrode. 


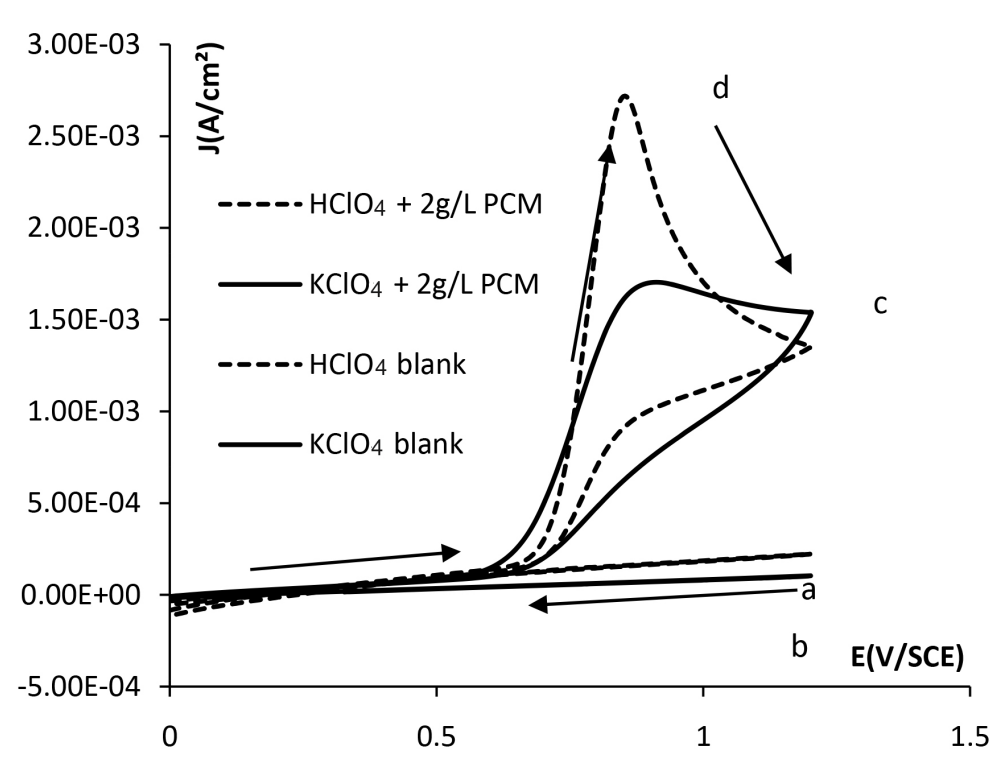

Figure 1. $\mathrm{Cv}$ voltammograms of $\mathrm{BDD}$ electrode in $\mathrm{HClO}_{4} 0.1 \mathrm{M}$ and $\mathrm{KClO}_{4}$ $0.1 \mathrm{M}$ electrolytes blank and containing $2 \mathrm{~g} / \mathrm{L}$ of paracetamol: Working electrode: DDB $\left(1 \mathrm{~cm}^{2}\right)$, Counter electrode: Pt wound, Reference electrode: SCE. Scanning rate: $50 \mathrm{mV} / \mathrm{s}$.

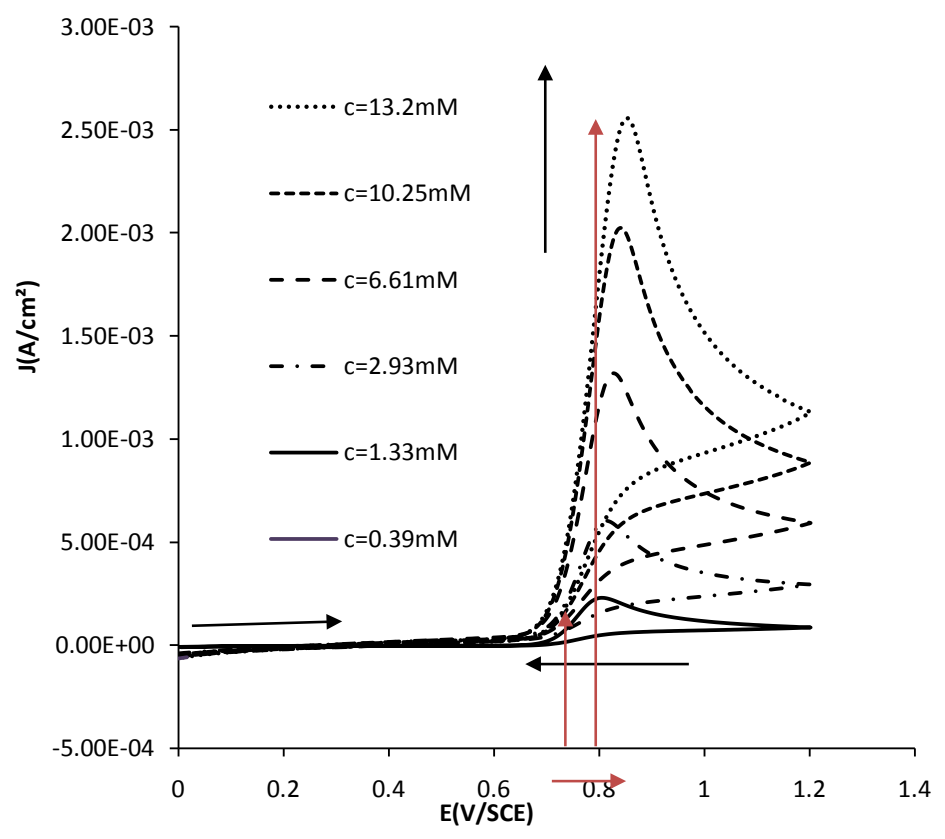

(a)

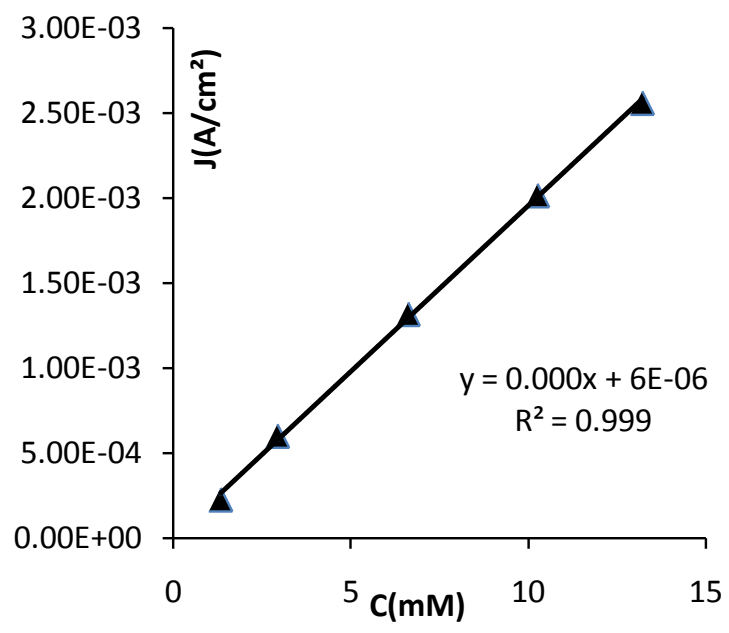

(b)

Figure 2. Cyclic voltammograms for different concentrations of paracetamol in $0.1 \mathrm{M} \mathrm{HClO}_{4}$ solution. Working electrode: DDB $\left(1 \mathrm{~cm}^{2}\right)$; Counter electrode: Pt wound; Reference electrode: SCE; Scanning rate: $50 \mathrm{mV} / \mathrm{s}$.

\subsection{Influence of the Potential Scan Rates}

The electrochemical oxidation process related to the oxidation of PCM by tackling the influence of the potential scan rate was carried out using CV techniques. The CV voltammogram of paracetamol exhibited also only one anodic peak, with no peak on the reverse scan (Figure 3(a)), indicating the totally irreversible 


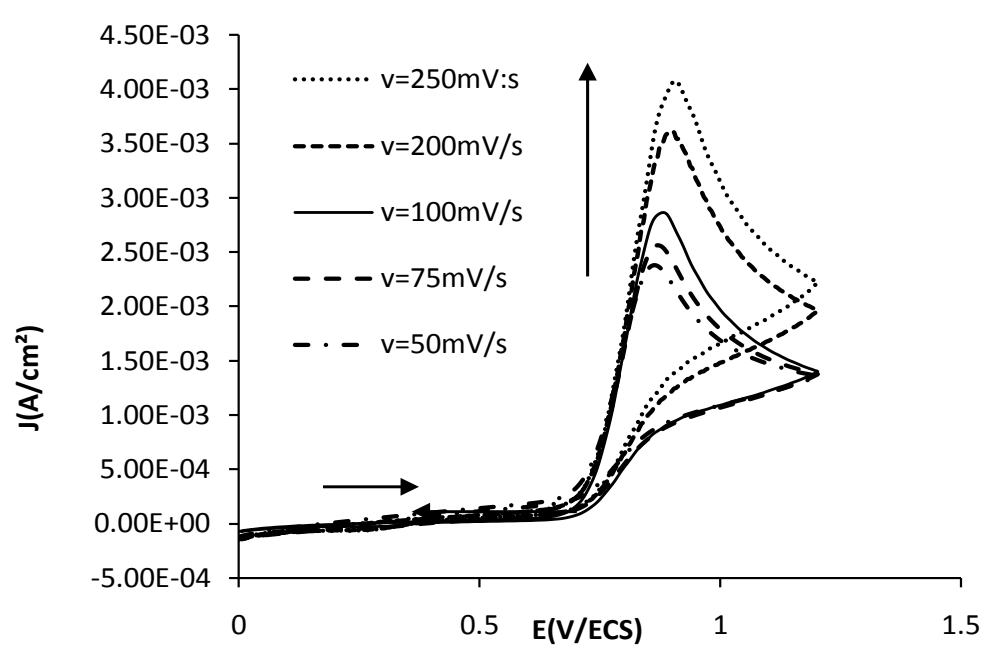

(a)

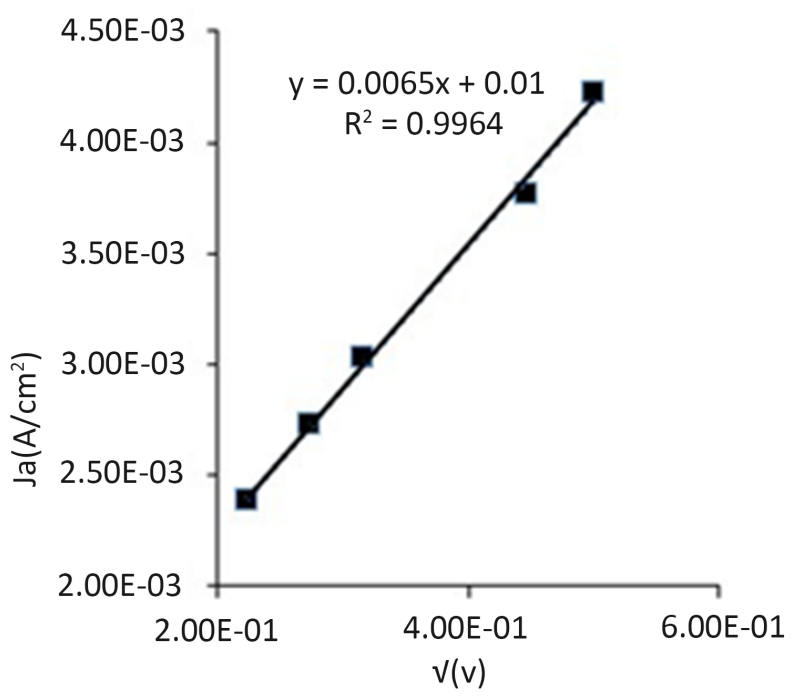

(b)

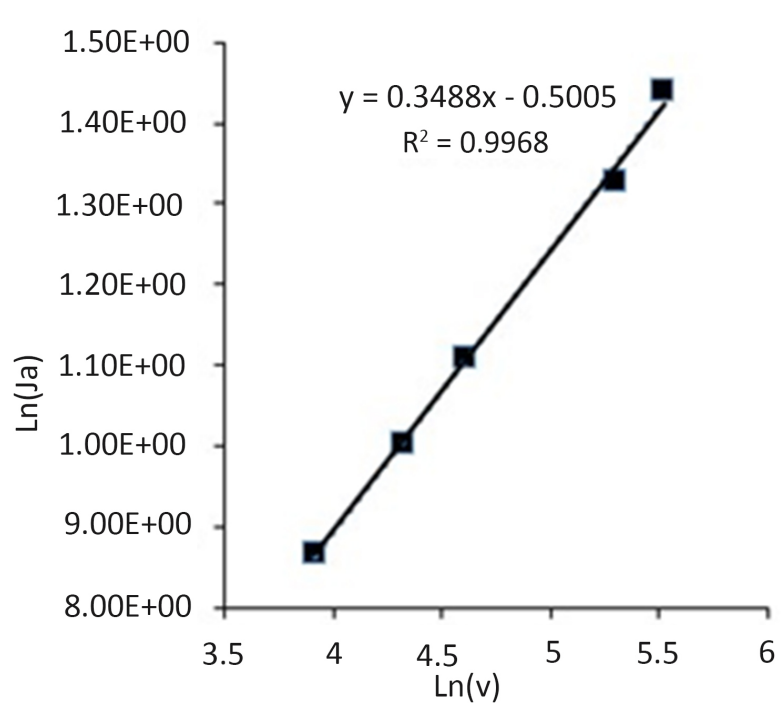

(c)

Figure 3. Cyclic voltammograms in a $0.1 \mathrm{M} \mathrm{HClO}_{4}$ solution containing $2 \mathrm{~g} / \mathrm{L}$ PCM at different scans (a); evolution as a function of the square root of the scanning speed of the anodic peak currents (b) and evolution as a function of the logarithm of the scanning speed of the anodic peak currents (c); Working electrode: DDB $\left(\mathrm{S}=1 \mathrm{~cm}^{2}\right)$, against electrode: Pt wound, Reference: SCE. Scan rate $=50 \mathrm{mV} \cdot \mathrm{s}^{-1}, \mathrm{~T}=25^{\circ} \mathrm{C}$.

nature of the electrode reaction. In addition, for an irreversible oxidation process, the peak potential (Ep) shifts to less positive values as the potential scan rates increase. That results shows also that the paracetamol oxidation process is irreversible [30].

The oxidation peak current density was plotted against the square root of the potential scan rates and the result is illustrated in Figure 3(b). That figure shows a straight line $\left(\mathrm{Ja}=0.0065 \mathrm{v}^{1 / 2}+0.001\right)$ with a correlation coefficient of 0.9964 (closed to 1). Moreover, the logarithm of the oxidation peak current density against the logarithm of the potential scan rates leads to Figure $3(\mathrm{c})$. This figure shows a straight line $(\ln J a=0.3488 \ln v-0.5005)$ with a slope of 0.3488 which is closed to theoretical value 0.5 . All those findings indicated that the PCM oxida- 
tion process is predominantly diffusion-controlled [30].

\subsection{Influence of the $\mathrm{pH}$}

The effect of the $\mathrm{pH}$ on the oxidation of paracetamol was studied in $0.1 \mathrm{M}$ $\mathrm{HClO}_{4}$ in the $\mathrm{pH}$ range from 0.217 to 11.18 by cyclic voltammetry. Figure 4 shows the recorded voltammograms. The shape of the oxidation peak changes from narrow to a broad peak when the $\mathrm{pH}$ of the solution passes from acidic $\mathrm{pH}$ to the alkaline $\mathrm{pH}$. As the $\mathrm{pH}$ increases, the oxidation peak changes to an oxidation wave. That the wave is very pronounced in the very alkaline medium $(\mathrm{pH}=$ 11.18). This result is probably explained by a very strong electrostatic repulsion effect between the surface of the electrode material and the species in solution, in particular, the PCM molecules. The well-resolved oxidation peak observed in a very acid medium $(\mathrm{pH}=0.217)$ could be explained by a predisposition of the DDB surface induced by this $\mathrm{pH}$, which allows electrons and protons exchanges at the electrode/electrolyte interface.

The peak potential of the oxidation peak shifted toward positive values as the $\mathrm{pH}$ increases (Figure 4). These can be explained by changes in protonation of the acid-base functions in the paracetamol molecules. In other word, proton takes part in the electrochemical reactions of paracetamol [30].

From this study and that performed on graphite electrodes [31], two protons were transferred in the reaction. The paracetamol oxidation could be a twoelectron and two-proton process as given below in Scheme 1.

The CV technique allowed to observe that the PCM oxidation process is irreversible on $\mathrm{BDD}$ electrode with a higher and well-resolved oxidation peak in acidic medium compared to the alkaline medium. The oxidation peak current density of the PCM varies linearly against its concentrations and the square root of its potential scan rates indicating the irreversible nature of the reaction taking

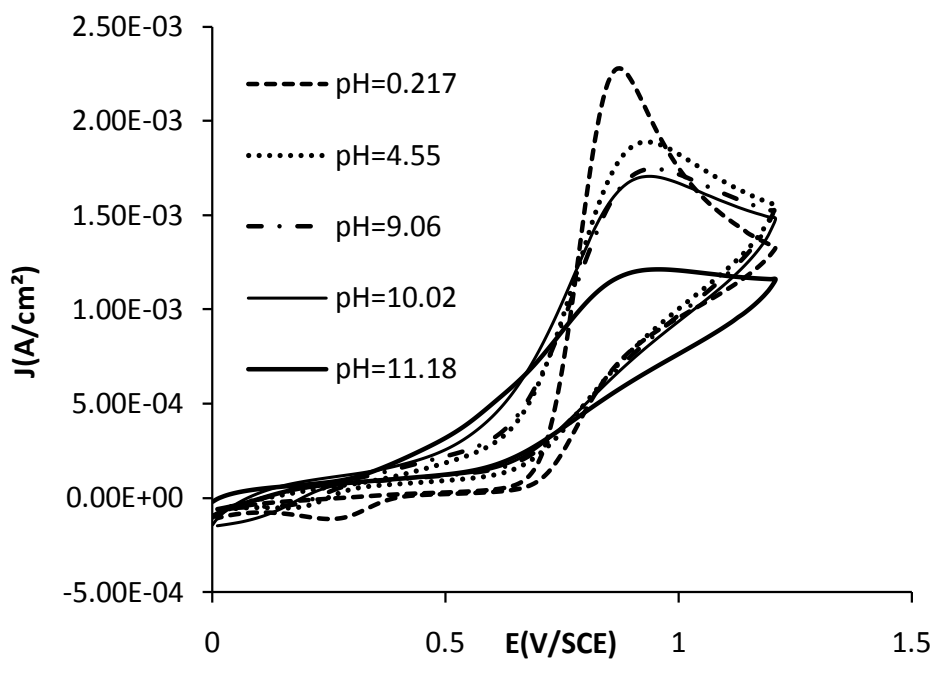

Figure 4. Cyclic voltammograms at different $\mathrm{pH}$ of $0.1 \mathrm{M} \mathrm{HClO}_{4}$ solution containing $2 \mathrm{~g} / \mathrm{L}$ PCM; AND: DDB $\left(1 \mathrm{~cm}^{2}\right)$, CE: Pt wound, ER: SCE. $\mathrm{V}=100 \mathrm{mV} / \mathrm{s}$. 


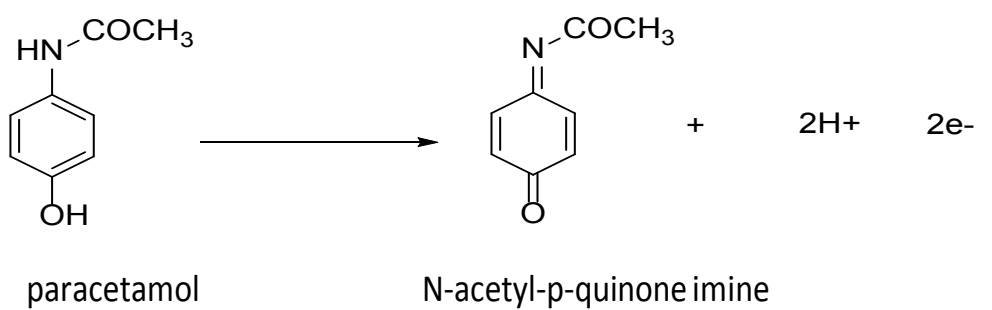

Scheme 1. Probable oxidation mechanism of paracetamol on BDD electrode.

place on the DDB surface. However, this technique did not allow us to determine very small quantities of pharmaceuticals in aqueous solution with the DDB electrode. In this case, the differential pulse voltammetry technique, a more sensitive technique, is used in this to develop a voltammetric technique to determine and quantify the drug in pharmaceutical formulation. For such technique, it is better to investigate the optimized conditions for which it can be properly used.

\subsection{Optimization of DPV Parameters}

Due to the fact that the potential modulation parameters, such as pre-treatment potential (Ep), pre-treatment time $\left(t_{\mathrm{Ep}}\right)$, modulation amplitude (MA), modulation time $\left(t_{M}\right)$ and potential step $(\Delta \mathrm{E})$ can affect peak height and peak potential, the optimization of these parameters has been performed.

During the adjustment of the above parameters, each parameter was changed, while the others were kept constant for a concentration of $1.32{ }^{*} 10^{-2} \mathrm{~mol} \cdot \mathrm{L}^{-1}$ of PCM in $0.1 \mathrm{M} \mathrm{HClO}_{4}$. The obtained results are shown in Figure 5.

Bearing in mind that the analytical performance of BDD electrodes depends on their surface termination (e.g. hydrogen or oxygen terminated) [27] [32], the effect of different electrochemical pretreatments of the BDD electrode on its Analytical response in $2 \mathrm{~g} / \mathrm{L} \mathrm{PCM}$ containing $0.1 \mathrm{M} \mathrm{HClO}_{4}$ was studied. Thus, the BDD electrode was anodically $(+2 \mathrm{~V}, 15 \mathrm{~s})$ or cathodically $(-2 \mathrm{~V} ; 15 \mathrm{~s})$ pretreated in a $0.5 \mathrm{~mol} \cdot \mathrm{L}^{-1} \mathrm{H}_{2} \mathrm{SO}_{4}$ solution. The analytical response of this electrode was monitored and recorded in the potential range varying between $-3 \mathrm{~V}$ and $+2 \mathrm{~V}$ (Figure 5(a)). As can be seen in Figure 5(a), the cathodic pretreatment leads to a better peak current density (better repeatability was also found), compared to the anodic pretreatment indicating that the cathodically pretreatment of the electrode leads to a higher electrochemical activity for the oxidation of PCM on the electrode, as it is observed in several other analytes [33]. The influence of the duration (15 to $300 \mathrm{~s}$ ) of the cathodic pretreatment of the BDD electrode on its analytical signal was also studied. Greater peak current amplitude was achieved with 90 s pretreatment. Thus, all of the following analytical determinations of PCM were made with the BDD cathodically pretreated electrode $\left(\mathrm{Ep}=-2 \mathrm{~V}, \mathrm{t}_{\mathrm{Ep}}=90 \mathrm{~s}\right.$, Figure $\left.5(\mathrm{~b})\right)$, which provided a predominantly hydrogen-terminated surface of the electrode. This pretreatment, performed daily before starting the voltammetric measurements, was always preceded by an anodic pretreatment $(+2 \mathrm{~V}, 15 \mathrm{~s})$ to clean the BDD surface from contaminant oxidant. This pretreatment coupling the anodically and cathodically technique led to 


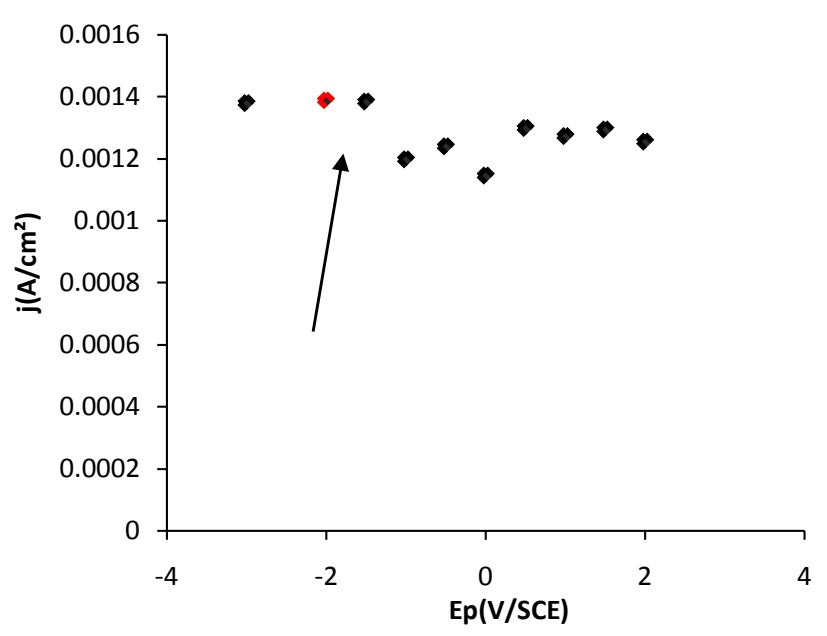

(a)

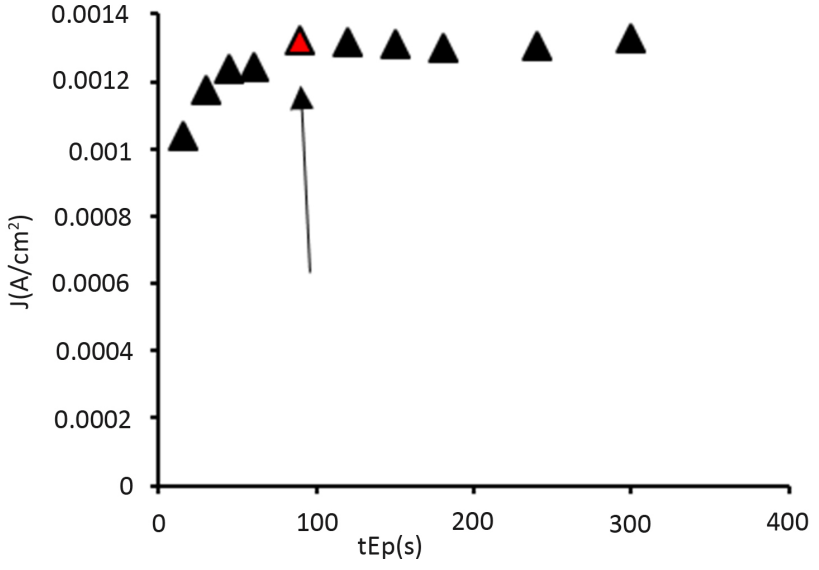

(b)

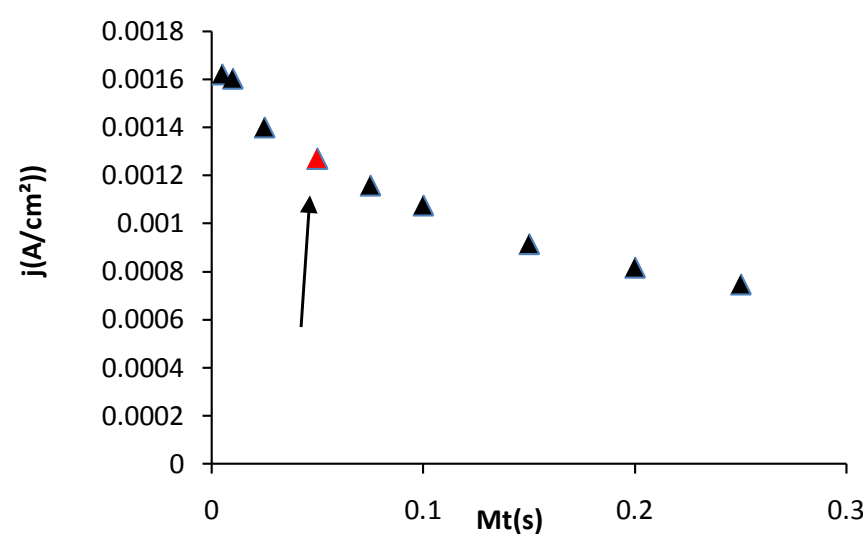

(d)

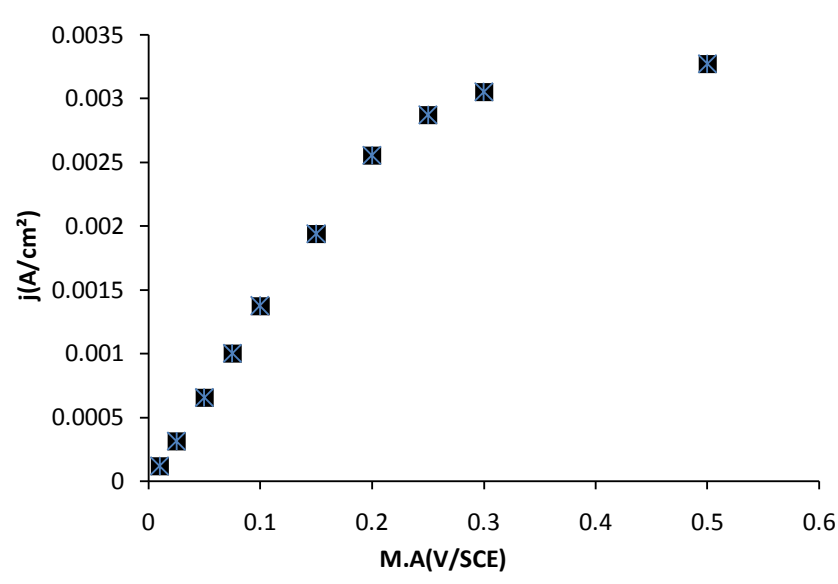

(c)

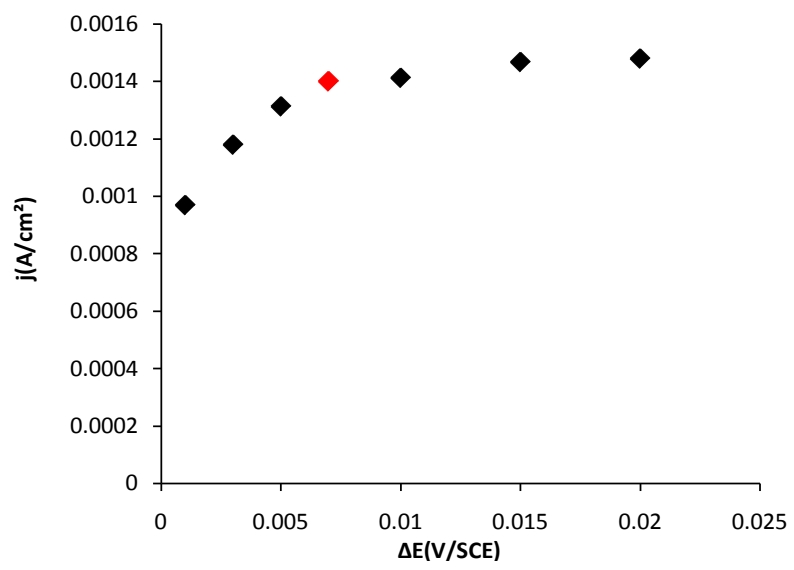

(e)

Figure 5. The effect of optimization of the parameters of $1.32 \times 10^{-2} \mathrm{~mol} \mathrm{~L}^{-1} \mathrm{Jma}$ obtained at BDD electrode in $\mathrm{HClO}_{4} 0.1 \mathrm{M}^{\mathrm{pH}}$ 0.217; (a) pretreatment potential, (b) pretreatment time, (c) modulation amplitude (MA), (d) modulation time (Mt) and (e) step potential $(\Delta \mathrm{E})$.

excellent repeatability in the determination of PCM on BDD. The effect of the modulation amplitude (MA) on the PCM oxidation peak current was also studied. The MA investigated varies between 10 and $500 \mathrm{mV}$. In this investigation, 
the potential was fixed (Figure 5(c)). In the MA studied range, the symmetrical voltammogram relative to its peak, without distortion and whose peak current density is the highest was obtained with a modulation amplitude of $100 \mathrm{mV}$. The influence of the modulation time (Mt) on the PCM oxidation current peak density has been studied in the range $5 \mathrm{~ms}$ to $250 \mathrm{~ms}$ (Figure 5(d)). It has been found that the analytic signal of the PCM oxidation current peak density decreased with Mt. The best results have been obtained for a modulation time of 50 ms. In addition, the influence of the potential step $(\Delta \mathrm{E})$ was studied in the interval between $1 \mathrm{mV}$ and $20 \mathrm{mV}$ (Figure 5(e)). The PCM oxidation peak current increases with the increase of $\Delta \mathrm{E}$, however, the potential step greater than $7 \mathrm{mV}$ caused a distortion in peak shape. Finally, $\Delta \mathrm{E}=7 \mathrm{mV}$ was chosen in this work as the optimal value.

The pretreatment potential of $-2 \mathrm{~V}$, the pretreatment time of $90 \mathrm{~s}$, the modulation amplitude of $100 \mathrm{mV}$, the modulation time of $50 \mathrm{~ms}$ and the potential step of $7 \mathrm{mV}$ have been found to be the optimal values of the cited variables.

\subsection{Detection and Quantification of Paracetamol by DPV Method}

In order to validate this analytical method for the determination of PCM for pharmaceutical and environmental purposes, PCM signals at different concentrations were recorded on the BDD electrode in perchloric acid medium $(0.1 \mathrm{M}$ $\mathrm{HClO}_{4}$ ).

Figure 6(a) shows the voltammetric response of the oxidation peaks for each PCM concentration ranging from $0 \mu \mathrm{M}$ to $13.87 \mu \mathrm{M}$. The voltammograms recorded under the optimal conditions $\mathrm{Ep}=-2 \mathrm{~V}, \mathrm{t}_{\mathrm{Ep}}=90 \mathrm{~s}, \mathrm{MA}=0.1 \mathrm{~V}, \mathrm{t}_{\mathrm{M}}=0.05$ $s$ and $\triangle E p=0.007 \mathrm{~V}$ shows that the PCM oxidation peaks are all observed at the same potential $(\mathrm{E}=0.7 \mathrm{~V})$ regardless of its concentrations. It appears from Figure 6(b) that the intensity of the PCM oxidation peak current increases linearly with the concentration of paracetamol. The limit of detection and quantification are respectively $0.167 \mu \mathrm{M}$ and $0.559 \mu \mathrm{M}$ using the equations LOD $=3 \mathrm{~S}_{\mathrm{D}} / \mathrm{b}$ and $L O Q=10 S_{D} / b$ for their determination; $S_{D}$ is the standard deviation and $b$ the slope of the straight line in Figure 6(b) [34]. Three sets of independent measurements have been made. Five (05) different concentrations of the paracetamol (Cth) were used to determine the recovery rate. The results obtained are assigned in Table 1 . With the calibration curve obtained, the experimental concentration was calculated for each of the five (05) concentrations of the paracetamol used. The plot of the experimental concentration as a function of the theoretical concentration of paracetamol (Figure 6(c)) gives a straight line whose equation is: $C_{\exp }=0.9999 C_{\text {théo }}-0.0000002$ with $R^{2}=0.9999$. This line has a correlation coefficient which is substantially equal to 1 indicating a proportionality between the experimental concentration and the theoretical concentration, and also the reliability of the differential pulse voltammetric analysis method.

These results show a high recovery rate of the PCM by this method. That indicates that this method is suitable for the PCM determination analytically in its pharmaceutical formulation. 


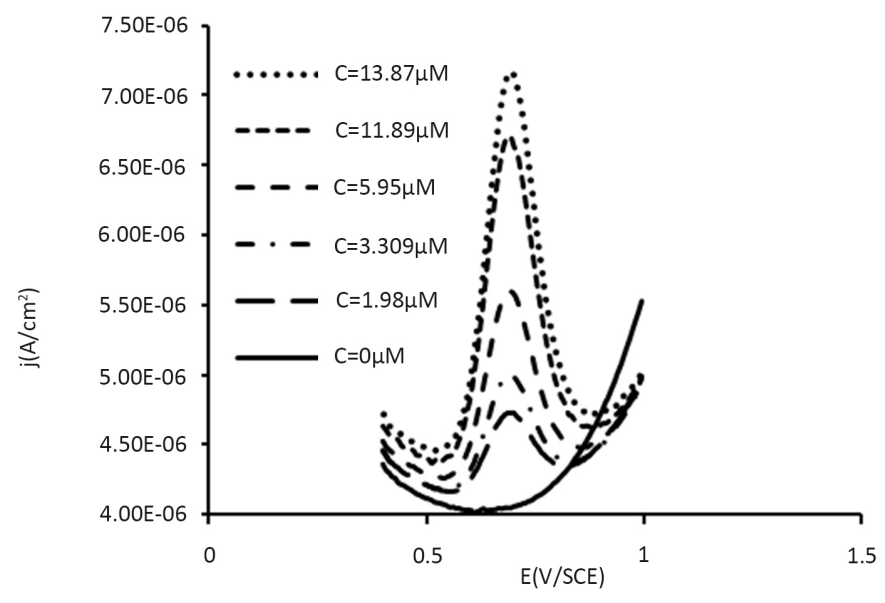

(a)

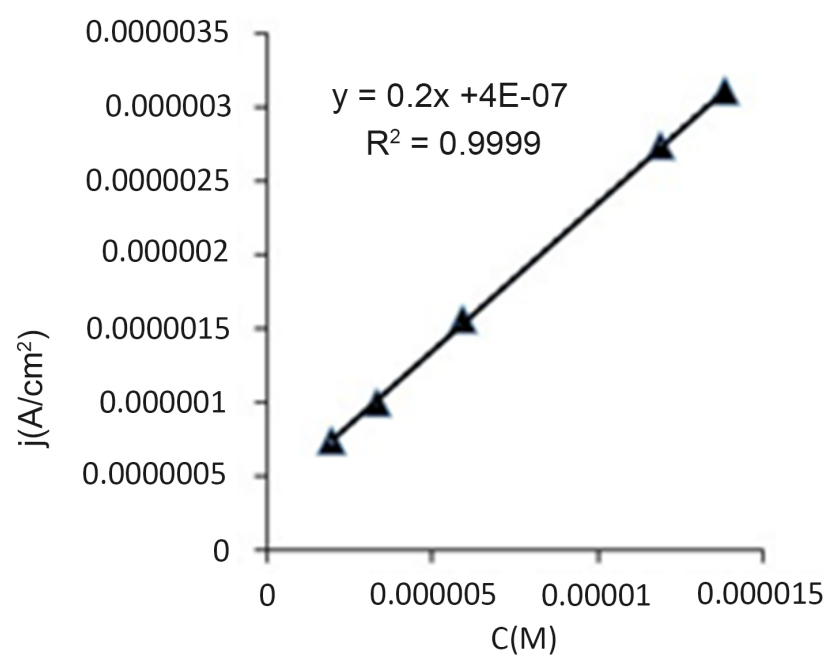

(b)

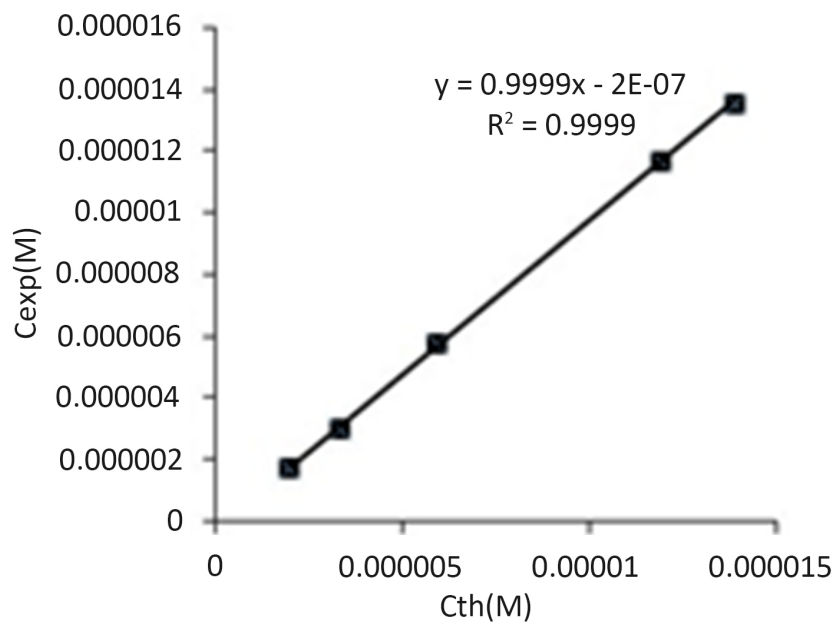

(c)

Figure 6. (a) Differential pulse voltammograms at different concentrations of paracetamol in $\mathrm{HClO}_{4}$ solution on $\mathrm{BDD}$ electrode by DPV; the concentration varies from $0 \mu \mathrm{M}$ to $19.8 \mu \mathrm{M}$, (b) Calibration curve of method and (c) curve of the experimental concentration of PCM versus the theoretical concentration of PCM.

Table 1. Recovery rate of the method.

\begin{tabular}{cccc}
\hline $\begin{array}{c}\text { Number } \\
\text { of the sample }\end{array}$ & $\begin{array}{c}\text { Concentration } \\
\text { introduced }(\mu \mathrm{M})\end{array}$ & $\begin{array}{c}\text { Concentration found } \\
(\mu \mathrm{M})\end{array}$ & Recovery rate \pm SD \\
\hline $\mathbf{1}$ & 1.98 & 1.707 & $86.25 \pm 0.92$ \\
$\mathbf{2}$ & 3.309 & 3.02 & $91.27 \pm 0.51$ \\
$\mathbf{3}$ & 5.95 & 5.78 & $97.17 \pm 0.72$ \\
$\mathbf{4}$ & 11.89 & 11.68 & $98.25 \pm 0.91$ \\
$\mathbf{5}$ & 13.87 & 13.56 & $97.80 \pm 0.14$ \\
\hline
\end{tabular}

\subsection{Comparison with Other Methods}

The determination of paracetamol by the differential pulse voltammetry in this study is compared with other methods described in literature such as square wave voltammetry (SWV) and cyclic voltammetry (CV) (Table 2). Although these last two methods offer interesting results with modified electrodes [35]-[45], 
Table 2. Comparison of the efficiency of some voltammetric methods in the determination of paracetamol.

\begin{tabular}{ccccc}
\hline Electrode & Method & $\begin{array}{c}\text { Linear range } \\
(\mu \mathrm{M})\end{array}$ & $\begin{array}{c}\text { Detection Limit } \\
(\text { LOD, } \mu \mathrm{M})\end{array}$ & Reference \\
\hline C60/GCE & DPV & $50-1500$ & 5 & 32 \\
PANI/MWCTs/GCE & SWV & $1-100$ & 0.25 & 33 \\
Nafion/TiO2-graphene/GCE & DPV & $1-100$ & 0.21 & 34 \\
AuNP-PGA/SWCNT & DPV & $8.3-145.6$ & 1.18 & 35 \\
BDDE & SWV & $0.4-100$ & 0.21 & 36 \\
PAY/nano-TiO2/GCE & DPV & $12-120$ & 2.0 & 37 \\
MIP & DPV & $1-4000$ & 0.33 & 38 \\
GR-CS & DPV & $1-100$ & 0.3 & 40 \\
CPE-CS & CV & $0.2-200$ & 0.508 & 41 \\
Nevirapine/GCE & DPV & $20-250$ & 0.77 & 42 \\
GI/GCE & DPV & $10-500$ & 2.7 & 43 \\
Graphene/GCE & SWV & $0.1-20$ & 0.032 & This work \\
BDD & DPV & $1.98-13.87$ & 0.16 &
\end{tabular}

Abbreviations: GCE: glassy carbon electrode; DPV: differential pulse voltammetry; SWV: square-wave voltammetry; PGA: poly (glutamic acid); PAY: poly (acid yellow 9); Nafion/ $\mathrm{TiO}_{2}$-graphene/GCE: Nafion/ $\mathrm{TiO}_{2}$-graphene modified glassy carbon electrode: $\mathrm{PAYnano}-\mathrm{TiO}_{2} / \mathrm{GCE}$ : poly (acid yellow 9)/nano- $\mathrm{TiO}_{2}$ modified glassy carbon electrode; C60/GCE: C60-modified glassy carbon electrode.; PANI-MWCNTs/GCE: a polyaniline-multi-walled carbon nanotubes (PANI-MWCNTs) composite modified electrode.

the DPV using as an electrochemical sensor, the boron-doped diamond electrode offers better analytical performances with a low detection limit $(0.16 \mu \mathrm{M})$, with the exception of Graphene/GCE [46].

Thus, the electroanalytical technique developed in this work is suitable for the detection and quantification of some trace organic pharmaceutical compounds present in wastewater.

\subsection{Interference Study}

The influence of some inorganic ions existing in physiological and environmental media has been studied on the detection of PCM. The interfering compounds selected are potassium nitrate $\left(\mathrm{K}^{+}, \mathrm{NO}_{3}^{-}\right)$, potassium chloride $\left(\mathrm{K}^{+}, \mathrm{Cl}^{-}\right)$, potassium sulphate $\left(2 \mathrm{~K}^{+}, \mathrm{SO}_{4}^{2-}\right)$ and potassium hydrogen phosphate $\left(2 \mathrm{~K}^{+}, \mathrm{HPO}_{4}^{2-}\right)$. Thus, to each $100 \mathrm{~mL}$ solution of PCM of $(0.25 \mathrm{~g} / \mathrm{L})$ in the $0.1 \mathrm{M} \mathrm{HClO}_{4}$ was successively added $0.5 ; 1 ; 1.5 ; 2 ; 2.5 ; 5$ and $10 \mathrm{~mL}$ of each interfering compound of concentration $25 \mathrm{~g} / \mathrm{L}$. From the recorded differential pulse voltammograms, the PCM oxidation peak current densities were deduced for each concentration of the interfering species. The interference $(\mathrm{X}, \mathrm{in} \%)$ of each compound on the PCM signal is calculated by the formula $\mathrm{X}=\left[\left(\mathrm{J}^{\prime} / J\right) \times 100\right]-100$ where $\mathrm{J}^{\prime}$ is the interfering signal of the PCM or the signal of the PCM in the presence of the interfering compound in solution, and J is the PCM signal in the absent of the interfering species. The results are gathered in Table 3 . 
Table 3. Influence of the concentration of the interfering compounds on PCM oxidation peak current.

\begin{tabular}{|c|c|c|}
\hline Interfering compounds & $\begin{array}{c}\text { Concentration in } \mathrm{g} / \mathrm{L} \text { of the } \\
\text { interfering added }\end{array}$ & $\begin{array}{c}\text { \% change in peak current } \\
\text { density in DPV } \\
\text { (with } \mathrm{J}_{\mathrm{PCM}}=100 \% \text { ) }\end{array}$ \\
\hline \multirow{7}{*}{$\left(\mathrm{K}^{+}, \mathrm{NO}_{3}^{-}\right)$} & 0.124 & -1.38 \\
\hline & 0.248 & +3.13 \\
\hline & 0.369 & -0.29 \\
\hline & 0.490 & +0.50 \\
\hline & 0.610 & -4.04 \\
\hline & 1.19 & +0.12 \\
\hline & 2.27 & +0.37 \\
\hline \multirow{7}{*}{$\left(\mathrm{K}^{+}, \mathrm{Cl}^{-}\right)$} & 0.124 & -2.42 \\
\hline & 0.248 & -2.17 \\
\hline & 0.369 & -4.68 \\
\hline & 0.490 & +5.06 \\
\hline & 0.610 & +4.06 \\
\hline & 1.19 & +0.97 \\
\hline & 2.27 & +4.99 \\
\hline \multirow{7}{*}{$\left(2 \mathrm{~K}^{+}, \mathrm{SO}_{4}^{2-}\right)$} & 0.124 & -3.02 \\
\hline & 0.248 & -0.71 \\
\hline & 0.369 & +1.77 \\
\hline & 0.490 & +0.577 \\
\hline & 0.610 & +3.88 \\
\hline & 1.19 & +3.75 \\
\hline & 2.27 & +0.46 \\
\hline \multirow{7}{*}{$\left(2 \mathrm{~K}^{+}, \mathrm{HPO}_{4}^{2-}\right)$} & 0.124 & -0.77 \\
\hline & 0.248 & -4.74 \\
\hline & 0.369 & -5.26 \\
\hline & 0.490 & -5.07 \\
\hline & 0.610 & -5.45 \\
\hline & 1.19 & -5.04 \\
\hline & 2.27 & -4.03 \\
\hline
\end{tabular}

These results show that the ions such as $\mathrm{K}^{+}, \mathrm{Cl}^{-}, \mathrm{SO}_{4}^{2-}, \mathrm{NO}_{3}^{-}$and $\mathrm{HPO}_{4}^{2-}$, which are 100 times more concentrated than paracetamol produce a negligible effect on its oxidation peak current in $0.1 \mathrm{M} \mathrm{HClO}_{4}$. The relative error recorded on the PCM signal is about $\pm 5 \%$, which is the acceptable tolerance limit of the concentration of the interfering compounds or substances added. It can consider that there has been no interference with the above-mentioned ions on the oxidation of PCM in the acidic medium. Such result indicated that this technique can be employed to determine the pharmaceuticals in highly loaded media with inorganic ions. 


\section{Conclusion}

A simple, sensitive, selective DPV technique for the quantitative determination of paracetamol based on its electrochemical oxidation at BDD electrode was established. From CV and DPV measurements, it appeared that the electrode reaction process is irreversible. Paracetamol was successfully determined in $\mathrm{HClO}_{4}$ in tablet doses by DPV technique. DPV is found to be suitable for PCM analysis and no interference was observed in the presence of highly concentrated inorganic ions. This technique can be used directly to analyze pharmaceuticals.

\section{Aknowledgements}

We are thankful to the Swiss National Funds for its financial support. They funded the project (IZ01Z0_146919) which durability helped this work to be undertaken.

\section{Conflicts of Interest}

The authors declare no conflicts of interest regarding the publication of this paper.

\section{References}

[1] Wan, Q., Wang, X., Yu, F., Wang, X. and Yang, N. (2009) Poly (Taurine)/MWNTModified Glassy Carbon Electrodes for the Detection of Acetaminophen. Journal of Applied Electrochemistry, 39, 785-790. https://doi.org/10.1007/s10800-008-9721-1

[2] https://www.drugs.com/paracetamol.html

[3] Lourencao, B.C., Medeiros, A., Rocha-Filho, R.C., Mazo, H. and Fatibello-Filho, O. (2009) Simultaneous Voltammetric Determination of Paracetamol and Caffeine in Pharmaceutical Formulations Using a Boron-Doped Diamond Electrode. Talanta, 78, 748-752. https://doi.org/10.1016/j.talanta.2008.12.040

[4] Nikolaou, A., Meric, S. and Fatta, D. (2007) Occurrence Patterns of Pharmaceuticals in Water and Wastewater Environments. Analytical and Bioanalytical Chemistry, 387, 1225-1234. https://doi.org/10.1007/s00216-006-1035-8

[5] Bosch, M.E., Sanchez, A.J.R., Rojas, F.S. and Ojeda, C.B. (2006) Determination of Paracetamol: Historical Evolution. Journal of Pharmaceutical and Biomedical Analysis, 42, 291-321. https://doi.org/10.1016/j.jpba.2006.04.007

[6] Sultan, M.A., Maher, H.M., Alzoman, N.Z., Alshehri, M.M., Rizk, M.S., Elshahed, M.S. and Olah, L.V. (2013) Capillary Electrophoretic Determination of Antimigraine Formulations Containing Caffeine, Ergotamine, Paracetamol and Domperidone or Metoclopramide. Journal of Chromatographic Science, 51, 502-510. https://doi.org/10.1093/chromsci/bms175

[7] Abdelaleem, E.A. and Abdelwahab, N.S. (2013) Validated Stability Indicating RP-HPLC Method for Determination of Paracetamol, Methocarbamol and Their Related Substances. Analytical Methods, 5, 541-545. https://doi.org/10.1039/C2AY26085A

[8] Lou, H.G., Yuan, H., Ruan, Z.R. and Jiang, B. (2010) Simultaneous Determination of Paracetamol, Pseudoephedrine, Dextrophan and Chlorpheniramine in Human Plasma by Liquid Chromatography-Tandem Mass Spectrometry. Journal of Chromatography B, 878, 682-688. https://doi.org/10.1016/j.jchromb.2010.01.005 
[9] Abirami, G. and Vetrichelvan, T. (2013) Simultaneous Determination of Tolperisone and Paracetamol in Pure an Fixed Dose Combination by UV-Spectrophotometry. International Journal of Pharmacy and Pharmaceutical Sciences, 5, 488-492.

[10] Khanmohammadi, M., Soleimani, M., Morovvat, F., Bagheri Garmarudi, A., Khalafbeigi, M. and Ghasemi, K. (2012) Simultaneous Determination of Paracetamol and Codeine Phosphate in Tablets by TGA and Chemometrics. Thermochimica Acta, 530, 128-132. https://doi.org/10.1016/j.tca.2011.12.009

[11] Gupta, V.K., Sethi, B., Sharma, R.A., Agarwal, S. and Bharti, A. (2013) Mercury Selective Potentiometric Sensor Based on Low Rim Functionalized Thiacalix [4]-Arene as a Cationic Receptor. Journal of Molecular Liquids, 177, 114-118. https://doi.org/10.1016/j.molliq.2012.10.008

[12] Foroughi, M.M., Beitollahi, H., Tajik, S., Hamzavi, M. and Parvan, H. (2014) Hydroxylamine Electrochemical Sensor Based on a Modified Carbon Nanotube Paste Electrode: Application to Determination of Hydroxylamine in Water Samples. International Journal of Electrochemical Science, 9, 2955-2965.

[13] Saraswathyamma, B., Grzybowska, I., Orlewska, C., Radecki, J., Dehaen, W., Kumar, K.G. and Radecka, H. (2008) Electroactive Dipyrromethene-Cu (II) Monolayers Deposited onto Gold Electrodes for Voltammetric Determination of Paracetamol. Electroanalysis, 20, 2317-2323. https://doi.org/10.1002/elan.200804328

[14] Fang, Y.Z., Long, D. and Ye, J. (1997) Study of Acetaminophen by Parallel Incident Spectroelectrochemistry. Analytica Chimica Acta, 342, 13-21. https://doi.org/10.1016/S0003-2670(96)00619-8

[15] Engin, C., Yilmaz, S., Saglikoglu, G., Yagmur, S. and Sadikoglu, M. (2015) Electroanalytical Investigation of Paracetamol on Glassy Carbon Electrode by Voltammetry. International Journal of Electrochemical Science, 10, 1916-1925.

[16] Gowda, J.I., Gunjiganvi, D.G., Sunagar, N.B., Bhata, M.N. and Nandibewoor, S.T. (2015) MWCNT-CTAB Modified Glassy Carbon Electrode as a Sensor for the Determination of Paracetamol. RSC Advances, 5, 49045-49053. https://doi.org/10.1039/C5RA05802C

[17] Baranowska, I., Markowski, P., Gerle, A. and Baranowski, J. (2008) Determination of Selected Drugs in Human Urine by Differential Pulse Voltammetry Technique. Bioelectrochemistry, 73, 5-10. https://doi.org/10.1016/j.bioelechem.2008.04.022

[18] Norouzi, P., Dousty, F., Ganjali, M.R. and Daneshgar, P. (2009) Dysprosium Nanowire Modified Carbon Paste Electrode for the Simultaneous Determination of $\mathrm{Na}$ proxen and Paracetamol: Application in Pharmaceutical Formulation and Biological Fluid. International Journal of Electrochemical Science, 4, 1373-1386.

[19] Beitollahi, H., Mohadesi, A., Mohammadi, S. and Akbari, A. (2012) Electrochemical Behavior of a Carbon Paste Electrodemodified with 5-Amino-3',4'-Dimethyl-Biphenyl-2-ol/Carbon Nanotube and Its Application for Simultaneous Determination of Isoproterenol, Acetaminophen and N-Acetylcysteine. Electrochimica Acta, 68, 220-226. https://doi.org/10.1016/j.electacta.2012.02.072

[20] Lourencao, B.C., Medeiros, R.A., Rocha-Filho, R.C., Mazo, L.H. and Fatibello-Filho, O. (2009) Simultaneous Voltammetric Determination of Paracetamol and Caffeine in Pharmaceutical Formulations Using a Boron-Doped Diamond Electrode. Talanta, 78, 748-752. https://doi.org/10.1016/j.talanta.2008.12.040

[21] https://www.gdscorp.com/blog/the-pros-and-cons-of-electrochemical-sensors

[22] Hupert, M., Muck, A., Wang, J., Stotter, J., Cvakova, Z., Haymond, S., Show, Y. and Swain, G.M. (2003) Square-Wave Voltammetry Determination of Aspartame in Dietary Products Using a Boron-Doped Diamond Electrode. Diamond and Related 
Materials, 12, 1940-1949. https://doi.org/10.1016/S0925-9635(03)00260-7

[23] Salazar-Banda, G.R., Andrade, L.S., Nascente, P.A.P., Pizani, P.S., Rocha-Filho, R.C. and Avaca, L.A. (2006) The Changing Electrochemical Behaviour of Boron-Doped Diamond Surfaces with Time after Cathodic Pre-Treatments. Electrochimica Acta, 51, 4612-4619. https://doi.org/10.1016/j.electacta.2005.12.039

[24] Suffredini, H.B., Pedrosa, V.A., Codognoto, L., Machado, S.A.S., Rocha-Filho, R.C. and Avaca, L.A. (2004) Enhanced Electrochemical Response of Boron-Doped Diamond Electrodes Brought on by a Cathodic Surface Pre-Treatment. Electrochimica Acta, 49, 4021-4026. https://doi.org/10.1016/j.electacta.2004.01.082

[25] Sartori, E.R., Medeiros, R.A., Rocha-Filho, R.C. and Fatibello-Filho, O. (2009) Square-Wave Voltammetric Determination of Acetylsalicylic Acid in Pharmaceutical Formulations Using a Boron-Doped Diamond Electrode without the Need of Previous Alkaline Hydrolysis Step. Journal of the Brazilian Chemical Society, 20, 360-366. https://doi.org/10.1590/S0103-50532009000200022

[26] Medeiros, R.A., Carvalho, A.E., Rocha-Filho, R.C. and Fatibello-Filho, O. (2009) Simultaneous Differential Pulse Voltammetric Determination of Sulfamethoxazole and Trimethoprim on a Boron-Doped Diamond Electrode. Electroanalysis, 21, 1475-1480. https://doi.org/10.1002/elan.200804551

[27] Medeiros, R.A., Carvalho, A.E., Rocha-Filho, R.C. and Fatibello-Filho, O. (2008) Simultaneous Square-Wave voltammetric Determination of Aspartame and Cyclamate Using a Boron-Doped Diamond Electrode. Talanta, 76, 685-689. https://doi.org/10.1016/j.talanta.2008.04.015

[28] Edyta, W., Ewa, C., Elzbieta, K. and Jacek, R. (2015) Voltammetric Study of the Behaviour of N-Acetyl-p-Aminophenol in Aqueous Solutions at a Platinum Electrode. Comptes Rendus Chimie, 18, 993-1000. https://doi.org/10.1016/j.crci.2015.06.017

[29] He, Y.P., Dong, Y.J., Huang, W.M., Tang, X.Q., Liu, H.H., Lin, H.B. and Li, H.D. (2015) Investigation of Boron-Doped Diamond on Porous Ti for Electrochemical Oxidation of Acetaminophen Pharmaceutical Drug. Journal of Electroanalytical Chemistry, 759, 169-173. https://doi.org/10.1016/j.jelechem.2015.11.011

[30] Yagmur, S., Yilmaz, S., Sadikoglu, M., Saglikoglu, G., Yildiz, M., Yengin, C. and Kilinc, E. (2013) Electrooxidation of Phenazopyridine Hydrochloride and Its Voltammetric and HPLC Determination in Human Urine and Tablet Dosage Form. International Journal of Electrochemical Science, 8, 6818.

[31] Guan, X.S. and Zhang, H. (2008) Electrochemical Behavior and Differential Pulse Voltammetric Determination of Paracetamol at a Carbon Ionic Liquid Electrode. Analytical and Bioanalytical Chemistry, 391, 1049-1055. https://doi.org/10.1007/s00216-008-2096-7

[32] Granger, M.C., Witek, M., Xu, J.S., Wang, J., Hupert, M., Hanks, A., Koppang, M.D., Butler, J.E., Lucazeau, G., Mermoux, M., Strojek, J.W. and Swain, G.M. (2000) Standard Electrochemical Behavior of High-Quality, Boron-Doped Polycrystalline Diamond Thin-Film Electrodes. Analytical Chemistry, 72, 3793-3804.

https://doi.org/10.1021/ac0000675

[33] Medeiros, R.A., Lourenção, B.C., Rocha-Filho, R.C. and Fatibello-Filho, O. (2012) Simultaneous Voltammetric Determination of Synthetic Colorants in Food Using a Cathodically Pretreated Boron-Doped Diamond Electrode. Talanta, 97, 291-297. https://doi.org/10.1016/j.talanta.2012.04.033

[34] Saadati, N., Abdullah, M.P., Zakaria, Z., Sany, S.B.T., Rezayi, M. and Hassonizadeh, H. (2013) Limit of Detection and Limit of Quantification Development Procedures for Organochlorine Pesticides Analysis in Water and Sediment Matrices. Chemistry 
Central Journal, 7, Article No. 63. https://doi.org/10.1186/1752-153X-7-63

[35] Goyal, R.N. and Singh, S.P. (2006) Voltammetric Determination of Paracetamol at C60-Modified Glassy Carbon Electrode. Electrochimica Acta, 51, 3008-3012. https://doi.org/10.1016/j.electacta.2005.08.036

[36] Li, M.Q. and Jing, L.H. (2007) Electrochemical Behavior of Acetaminophen and Its Detection on the PANI-MWCNTs Composite Modified Electrode. Electrochimica Acta, 52, 3250-3257. https://doi.org/10.1016/j.electacta.2006.10.001

[37] Fan, Y., Liu, J.H., Lu, H.T. and Zhang, Q. (2011) Electrochemical Behavior and Voltammetric Determination of Paracetamol on $\mathrm{Nafion} / \mathrm{TiO}_{2}-\mathrm{Graphene}$ Modified Glassy Carbon Electrode. Colloids and Surfaces B: Biointerfaces, 85, 289-292. https://doi.org/10.1016/j.colsurfb.2011.02.041

[38] Bui, M.P.N., Li, C.A., Han, K.N., Pham, X.H. and Seong, G.H. (2012) Determination of Acetaminophen by Electrochemical Co-Deposition of Glutamic Acid and Gold Nanoparticles. Sensors and Actuators B, 174, 318-324. https://doi.org/10.1016/j.snb.2012.08.012

[39] Svorca, L., Sochra, J., Tomcik, P., Rievaja, M. and Bustin, D. (2012) Simultaneous Determination of Paracetamol and Penicillin V by Square-Wave Voltammetry at a Bare Boron-Doped Diamond Electrode. Electrochemical Acta, 68, 227-234. https://doi.org/10.1016/j.electacta.2012.02.071

[40] Kumar, S.A., Tang, C.F. and Chen, S.M. (2008) Electroanalytical Determination of Acetaminophen Using Nano- $\mathrm{TiO}_{2} /$ Polymer Coated Electrode in the Presence of Dopamine. Talanta, 76, 997-1005. https://doi.org/10.1016/j.talanta.2008.04.057

[41] Luo, J., Fan, C.H., Wang, X.H., Liu, R. and Liu, X.Y. (2013) A Novel Electrochemical Sensor for Paracetamol Based on Molecularly Imprinted Polymeric Micelles. Sensors and Actuators B, 188, 909-916. https://doi.org/10.1016/j.snb.2013.07.088

[42] Zheng, M.X., Gao, F., Wang, Q.X., Cai, X.L., Jiang, S.L., Huang, L.Z. and Gao, F. (2013) Electrocatalytical Oxidation and Sensitive Determination of Acetaminophen on Glassy Carbon Electrode Modified with Graphene-Chitosan Composite. Materials Science and Engineering C, 33, 1514-1520. https://doi.org/10.1016/j.msec.2012.12.055

[43] Bouabi, Y.E., Farahi, A., Labjar, N., Hajjaji, S.E.I., Bakasse, M. and Mhammedi, M.A.E.I. (2016) Square Wave Voltammetric Determination of Paracetamol at Chitosan Modified Carbon Paste Electrode: Application in Natural Water Samples, Commercial Tablets and Human Urines. Materials Science and Engineering. C, 8 , 70-77. https://doi.org/10.1016/j.msec.2015.08.014

[44] Tanuja, S.B., Kumara Swamy, B.E. and Pai, K.V. (2017) Electrochemical Determination of Paracetamol in Presence of Folic Acid at Nevirapine Modified Carbon Paste Electrode: A Cyclic Voltammetric Study. Journal of Electroanalytical Chemistry, 798, 17-23. https://doi.org/10.1016/j.jelechem.2017.05.025

[45] Fu, L., Xie, K.F., Zheng, Y.H., Zhang, L.X. and Su, W.T. (2018) Graphene Ink Film Based Electrochemical Detector for Paracetamol Analysis. Electronics, 7, 15. https://doi.org/10.3390/electronics7020015

[46] Kang, X., Wang, J., Wu, H., Liu, J., Aksay, I.A. and Lin, Y. (2010) A Graphene-Based Electrochemical Sensor for Sensitive Detection of Paracetamol. Talanta, 81, 754-759. https://doi.org/10.1016/j.talanta.2010.01.009 